\title{
PCNA EXPRESSION IN EPITHELIAL LININGS OF ODONTOGENIC CYSTS
}

J. Sudiono, R.B. Zain. PCNA expression in epithelial linings of odontogenic cysts. Annal Dent Univ Malaya 2003; 10: 1-5.

\section{ABSTRACT}

Proliferating Cell Nuclear Antigen (PCNA) is one of the several markers of cellular proliferation. Epithelial proliferations play a significant role in the behaviour of odontogenic lesions. The objective of this study was to describe and compare the distribution of PCNA expression within the epithelial linings of odontogenic cysts. A total of 49 cases of odontogenic cysts consisting of 18 radicular cysts, 16 dentigerous cysts, 15 odontogenic keratocysts (OKCs) was studied. All tissues were processed routinely prior to embedding in paraffin.

PCNA immunohistochemical staining was performed on 4 !-tm thick deparaffinized sections mounted on sialinized slides using the peroxidase antiperoxidase method. The distributions of PCNA expression in the cysts linings were noted and comparison was made qualitatively and quantitatively. PCNA labelling index was used for the quantitative assessment. The results showed that PCNA staining was distributed in the basal and supra basal cells for radicular cysts, dentigerous cysts, and OKCs. PCNA labelling index was highest in $\mathrm{OKC}(22.33 \pm 4.07)$. The high PCNA labelling index in $\mathrm{OKC}$ is indicative of high proliferative activity thus supporting previous reports of $\mathrm{OKC}$ as the most aggressive type of odontogenic cysts.

Key Words: immunostaining, PCNA, odontogenic cysts.

\section{INTRODUCTION}

Many researchers have studied the proliferative activity or biological activity of odontogenic lesions using different methods such as counting mitoses or immunohistochemical demonstration of proliferation markers (1). Epithelial proliferations playa significant role in the behaviour of odontogenic lesions. Proliferation activity is an important predictor of biologic behaviour of pathologic condition and as a potential guide for therapy. Deregulated cell proliferation may be an important change that signals premalignant transformation (2). Several markers of cellular proliferation including PCNA have been previously investigated as either diagnostic or prognostic markers in many disease states, including oral mucosal dysplasia and neoplasm (3-9). It was

\section{Original Article}

J. Sudionol, R.B. Zain²

JPathology Anatomy Department, Faculty of Dentistry, Trisakti University, Jakarta, INDONESIA

\author{
2Professor \\ Department of Oral Pathology, \\ Oral Medicine and Periodontology, \\ Faculty of Dentistry, University of Malaya, \\ Kuala Lumpur, MALAYSIA. \\ Corresponding author - Janti Sudiono
}

observed that the more aggressive behaviour of odontogenic keratocyst in nevoid basal cell carcinoma syndrome could be correlated with a higher rate of epithelial proliferations (1).

Previous studies on PCNA had demonstrated that among odontogenic cysts, the highest level of epithelial cell proliferation was in odontogenic keratocyst (10).

The objective of the present study was to describe and compare the distribution of PCNA expression within the epithelial linings of odontogenic cysts.

\section{MATERIALS AND METHODS}

Samples

The specimens used in this study were biopsy materials from the Department of Oral Pathology, Oral Medicine, and Periodontology, Dental Faculty, University of Malaya. The specimens were fixed in $10 \%$ buffered formalin and embedded in paraffin wax. The total number of samples are 49 (radicular cysts $=18$, dentigerous cysts $=16$, OKCs $=15$ ).

The inclusion criteria

All materials were assessed histologically by an oral pathologist (RBZ) and clinical data on tooth vitality and location of cysts in the jaws were obtained from the written submissions in the patient's biopsy forms.

The materials were included in this stud'y according to the following histopathological and clinical criteria:

A radicular cyst is a cyst which histologically consists of a non-keratinised stratified squamous epithelial lining with irregular rete processes and a dense fibrous connective tissue wall (11). Clinically, this lesion is associated with a non-vital tooth. 
A dentigerous cyst is a cyst which histologically consists of a non-keratinised stratified squamous epithelial lining and a fibrous connective tissue wall (11). Clinically/ radiologically, this lesion is associated with the crown of an impacted tooth.

An odontogenic keratocyst is a cyst which histologically consists of a parakeratinized or orthokeratinized stratified squamous epithelium with pallisading of basal cell nuclei, absence of rete processes and there is a fibrous connective tissue wall (11). Clinically/radiologically, this is a lesion in the jaw bone.

Demographic characteristics of the samples

The mean ages of the patients with radicular, dentigerous, and odontogenic cysts were $33.00 \pm 14.54$; $35.5 \pm 17.97 ; \quad 31.6 \pm 16.75$ years respectively. Table 1 showed the ethnic and gender distribution of the samples. All the patients with cystic lesions was predominantly in the Chinese ethnic group with female slightly higher, which were $61 \%(11 / 18)$ for radicular cyst, 63\% (10/16) for dentigerous cyst, 67\% (10/15) for OKCs.

Immunohistochemical staining of PCNA

The specimens were fixed in $10 \%$ buffered formalin and embedded in paraffin wax. PCNA immunohistochemistry staining was performed on 4 /lm thick deparaffinised sections mounted on sialinised slides and dried at $56^{\circ} \mathrm{C}$ for 30 minutes.

After dewaxing and rehydrating, the sections were immersed in $4.28 \mathrm{mM}$ citrate buffer at $\mathrm{pH} 6$ and treated by microwave for 12 minutes at $100^{\circ} \mathrm{C}$. This method was used to expose more antigenic sites in the tissue. The sections were then immersed in $3 \% \mathrm{H}_{2} \mathrm{O}_{2}$ in methanol to block endogenous peroxidase activity, followed by incubation in normal rabbit serum (NRS)
1: 20 for 20 minutes to block background peroxidase activity. Sections were incubated for two hours in a primary antibody (monoclonal anti PCNA antibody, clone PC-1O,Dako, A/S Denmark, 1: 100). The primary antibody which was bound to PCNA was detected using a secondary antibody (Biotinylated rabbit anti-mouse). The reaction products were visualised with an immunoperoxidase method using Avidin Biotin Complex-HRP (ABC) which can be used for all monoclonal antibodies. The peroxidase activity was developed and visualised by a chromogen solution consisting of $0.05 \%$ diamine benzidine hydrochloride (DAB) for 10 minutes to obtain a brown reaction product. Sections were counter stained with Meyer's haematoxylin and mounted in a mounting medium dibutyl phthalate in xylene. The negative control consisted of omitting the primary and secondary antibody. All dilutions were performed using Tris Buffered Saline.

Evaluations

The qualitative evaluation includes the recording of the presence or absence of the PCNA staining and describing its distribution. The quantitative evaluation was done by counting the number of positive nuclei under 20X objective in comparison with the total number of epithelial cells for three randomly selected fields.

\section{RESULTS}

The nuclear PCNA reactivity was detected as granular staining throughout the nucleoplasm. The PCNA positive nuclei $(\mathrm{PCNA}+)$ were distributed in the basal and supra basal cells for radicular cysts, dentigerous cysts, and OKCs (Figure 1-3).

Table 1. Ethnic and gender distribution of the samples

\begin{tabular}{|c|c|c|c|c|}
\hline $\begin{array}{l}\text { Ethnic } \\
\text { Groups }\end{array}$ & $\begin{array}{c}\text { Radicular }(\mathrm{N}=18) \\
\mathrm{n}(\%)\end{array}$ & $\begin{array}{c}\text { Dentigerous }(\mathrm{N}=16) \\
\mathrm{n}(\%)\end{array}$ & $\begin{array}{c}\text { OKC }(\mathrm{N}=15) \\
n(\%)\end{array}$ & $\begin{array}{c}\text { Total }(\mathrm{N}=49) \\
\mathrm{n}(\%)\end{array}$ \\
\hline \multicolumn{5}{|l|}{ Malay } \\
\hline Male & $0(0.00)$ & $4(25.00)$ & $0(0.00)$ & $4(8.16)$ \\
\hline Female & $1(5.56)$ & a $(0.00)$ & $0(0.00)$ & $1(2.04)$ \\
\hline \multicolumn{5}{|l|}{ Chinese } \\
\hline Male & $4(22.22)$ & $7(43.75)$ & $3(20.00)$ & $14(28.57)$ \\
\hline Female & 7 (38.89) & $3(18.75)$ & 7 (46.67) & 17 (34.69) \\
\hline \multicolumn{5}{|l|}{ Indians } \\
\hline Male & $4(22.22)$ & $1(6.25)$ & 2 (13.33) & 7 (14.29) \\
\hline Female & $2(11.11)$ & $0(0.00)$ & $3(20.00)$ & $5(10.20)$ \\
\hline \multicolumn{5}{|l|}{ Others } \\
\hline Male & $0(0.00)$ & $1(6.25)$ & $0(0.00)$ & $1(2.04)$ \\
\hline Female & $0(0.00)$ & $0(0.00)$ & $0(0.00)$ & $0(0.00)$ \\
\hline \multicolumn{5}{|l|}{ Total } \\
\hline Male & $8(44.44)$ & $13(81.25)$ & 5 (33.33) & $26(53.06)$ \\
\hline Female & $10(55.56)$ & $3(18.75)$ & a (66.67) & $23(46.94)$ \\
\hline
\end{tabular}




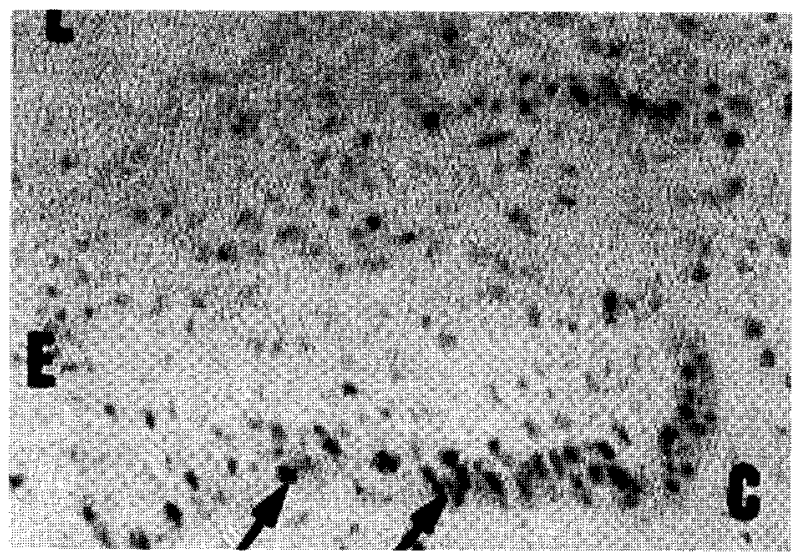

Figure 1: PCNA + nuclei (arrows) in basal and suprabasal cells of radicular cyst lining. $\mathrm{L}=$ lumen $\mathrm{E}=$ epithelium $\mathrm{C}=$ connective tissue (Original magnification 50x)

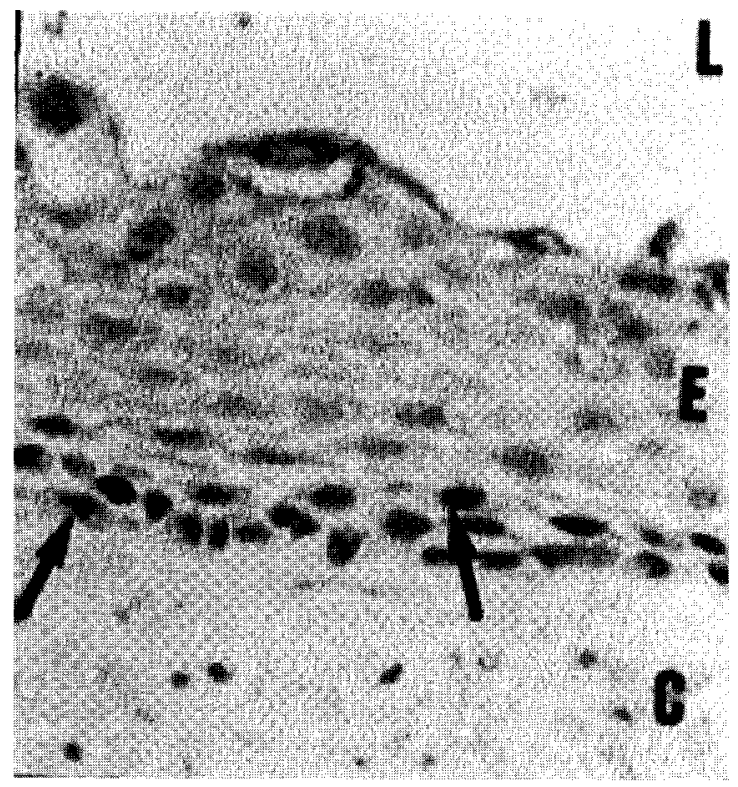

Figure 2: PCNA + nuclei (arrows) in the basal and suprabasal cells of dentigerous cyst lining.

$\mathrm{L}=$ lumen $\quad \mathrm{E}=$ epithelium

$\mathrm{C}=$ connective tissue $($ Original magnification 1OOx $)$

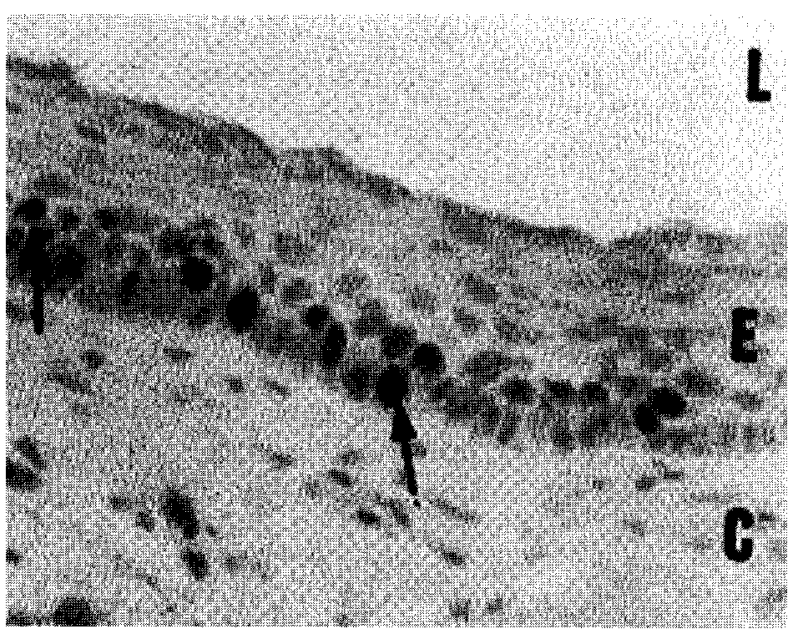

Figure 3: PCNA + nuclei (arrows) in the keratinised epithelial lining of $\mathrm{OKC}$ $\mathrm{L}=$ lumen $\quad \mathrm{E}=$ epithelium

$\mathrm{C}=$ connective tissue (Original magnification 1OOx)
Table 2. PCNA labelling index for radicular, dentigerous, and odontogenic keratocysts

\begin{tabular}{lll}
$\begin{array}{l}\text { Type of lesions } \\
(n=61)\end{array}$ & $\begin{array}{c}\text { Number of } \\
\text { lesions }\end{array}$ & $\begin{array}{l}\text { PCNN cells } \\
\text { (mean } \pm \text { SO) }\end{array}$ \\
\hline $\begin{array}{l}\text { Radicular cysts } \\
(n=18)\end{array}$ & $6(33.3 \%)$ & $10.39 \pm 2.18$ \\
$\begin{array}{l}\text { Dentigerous cysts } \\
(n=16)\end{array}$ & $8(50.0 \%)$ & $10.79 \pm 1.59$ \\
$\begin{array}{l}\text { Odontogenic keratocyst } \\
(n=15)\end{array}$ & $7(46.7 \%)$ & $22.33 \pm 4.07$
\end{tabular}

Table 2 shows that the PCNA labelling index (mean of PCNA + cells) for OKC was the highest $(22.33 \pm 4.07)$ among all the odontogenic cysts followed by that of dentigerous cyst $(10.79 \pm 1.59)$ and that of radicular cyst $(10.39 \pm 2.18)$.

\section{DISCUSSION}

Radicular and dentigerous cysts and OKCs are the most common type of odontogenic cysts found in dental practice. These cysts have different biologic activities. Most radicular cysts grow slowly and do not attain a large size. As the epithelium desquamates into the lumen, the protein content increased. Fluid enters the lumen in an attempt to equalize the osmotic pressure and slow enlargement occurs (12-13). The dentigerous cyst appears to have greater potential for ameloblastomatous transformation than all other jaw cysts (12-15). The clinicopathological features of OKC are quite different with that of other odontogenic cysts. The OKC shows a different growth mechanism and biologic behaviour from the more common dentigerous and radicular cysts. Radicular and dentigerous cysts continue to enlarge as a result of increased osmotic pressure within the lumen of the cyst, while in OKC the growth may be related to unknown factors inherent in the epithelium itself or enzymatic activity in the fibrous wall. According to Labban and Aghabeigi (1990), the presence of fenestrated capillaries in the keratocyst may indicate a rapid transfer of fluid to meet the demand of the relatively active proliferating epithelium which may be prompted by growth factors released from platelets in those thrombosed vessels (16). The OKC tends to expand antero-posteriorly in medulla without any bony expansion. -According to Waldron (1995), the aggressiveness of OKC may be due to many factors such as it being a multilocular cyst and the presence of growth epithelial factors within its epithelial lining (13). Browne and Gough (1972), and Regezi and Sciubba (1992) described that odontogenic cysts with ortho or parakeratinized epithelium as having a higher recurrence rate thus the high proliferative activity of the remaining epithelial cells after enucleation of cyst $(12,17)$. 
There were no records in the' biopsy forms indicating that the OKCs in this study is part of the nevoid basal cell carcinoma syndrome. In view of the rarity of this syndrome, it was assumed that most of the OKCs in this study were non-syndromic.

The PCNA labelling index of OKCs in this study was found to be the highest, as compared to that of dentigerous and radicular cyst (Table 2). This was in agreement with the study by Li et al (1995) (18) where another proliferation marker Ki-67 was used. These results were in keeping with the clinically more aggressive (proliferative) behaviour of $\mathrm{OKC}$ as compared to that of dentigerous and radicular cysts.

Li et al (1994) (10) had shown a supra basal distribution of PCNA positive cells in OKC whilst for dentigerous cyst the distribution was in basal area. These distributions of PCNA positive cells in OKC and dentigerous cyst were also shown in this study. In this study there was a basal and suprabasal distribution of PCNA positive cells for OKC and dentigerous cyst. In the radicular cyst, the distribution of PCNA positive cells was also in a basal and supra basal location.

This study also showed generally variable reactivity with many samples showing less intense PCNA expression. Thus the number of samples with intense PCNA expressions was low: $33.33 \%$ for radicular cysts, $50 \%$ dentigerous cysts, and $47 \%$ OKCs. This may be due to the fact that most of the specimens used were archival material (1981-1996) where there was no indication of their fixation time. According to $\mathrm{Yu}$ et al (1991) (7), to obtain a good result, the fixation time must not be more than 48 hours (6-48 hours). This view was also supported by Tsuji et al (1992 (19) who found that PCNA PC-1O reactivity was specific in the range of 6 to 48 hours in $10 \%$ formalin fixed paraffin sections. Pellegrini et al (1995) (20) reported that PCNA is very sensitive to the concentration and duration of formalin fixation, and also with the incubation time of primary antibody. Another reason for the variable reactivity is due to PCNA instability and this varies from cell to cell within the same specimen resulting in strong to weak immunostaining and rendering evaluation difficult. The weak PCNA staining observed may be due to the long half life of the PCNA protein (Hall et aI, 1990) (5).

\section{CONCLUSIONS}

The labelling index (mean) of PCNA positive cells in OKC was the highest among odontogenic cysts. The highest PCNA labelling index in OKC in this present study supported the previous reports that the $\mathrm{OKC}$ is the most aggressive type of odontogenic cysts.

\section{REFERENCES}

1. El Murtadi A, Grehan D, Toner M, Mc Cartan BE. PCNA staining in syndrome and non syndrome odontogenic keratocysts. Oral Surg Oral Med Oral Pathol 1996; 81: 217-220.

2. Mighell A. Proliferating cell nuclear antigen. Oral Surg Oral Med Oral Pathol 1995; 30: 3-4.

3. Garcia RL, Coltrera MD, Gown AMI. Analysis of proliferative grade using anti PCNA/cyclin monoclonal antibodies in fixed, embedded tissues. Comparison with flow cytometric analysis. Am J Patho11984; 134: 733-739.

4. Dawson AE, Norton JA, Weinber DS. Comparative assessment of proliferation and DNA content in breast carcinoma by image analysis and flow cytometry. Am J Patho11990; 136: 115-124.

5. Hall PA, Levison DA, Woods AL. Proliferating cell nuclear antigen (PCNA) immunolocalization in paraffin sections an index of cell proliferation with evidence of deregulated expression in some neoplasms. J Patho11990; 162: 285-294.

6. Allegranza A, Girlando S, Arrigont GL. Proliferating cell nuclear antigen expression in central nervous system neoplasms. Virchows Arch (A) $1991 ; 419: 417-423$.

7. Yu CC, Hall PA, Fletcher CDM, Camplejohns RS, Waseem NH, Lane DP, Levison DA. Haemangiopericytomas: the prognostic value of immunohistochemical staining with a monoclonal antibody to proliferating cell nuclear antigen (PCNA). Histopathology 1991; 19: 29-33.

8. Ogawa I, Takata T, Miyauchi M, Ito H, Ijuhin N, Nikai H. Proliferating cell nuclear antigen (PCNA) as a marker of proliferating cells in salivary gland tumors. Jpn J Oral Bioi 1992; 34: 454-457.

9. $\mathrm{Yu} \mathrm{C}$ and Filipe $\mathrm{M}$. Update on proliferation associated antibodies applicable to formalin fixed paraffin-embedded tissue and their clinical applications. Histochem 1993; 25: 843-853.

10. Li TJ, Browne RM and Matthews JB. Quantification of PCNA + cells within odontogenic jaw cyst epithelium. J Oral Pathol Med 1994; 23: 184-189.

11. Kramer IRH, Piridborg 11, Shear M. Histological typing of odontogenic tumours. Second edition. Springer-Verlag, Berlin, 1992; 34-42. 
12. Regezi JA and Sciuba 1. Clinocal-pathologic correlation. Second edition. Saunders. Philadelphia, 1993; 322-343.

13. Waldron CA. "Odontogenic cyst and tumours". In Oral and Maxillofacial Pathology. Edited by Neville BW, Damm DD, Allen OM, Bouquot JE. 1995; 103-106.

14. Robinson $\mathrm{L}$ and Martinez MG. Unicystic ameloblastoma. A prognostically distinct entity. Cance 1977; 40: 278-285.

15. Gardner 1981. Plexiform Unicystic Ameloblastoma. A Diagnostic Problem in Dentigerous Cysts. Cancer 1981; 15: 1359-1363.

16. Labban NG and Aghabeigi B. A Comparative Stereologic and Ultrastructural Study of Blood Vessels in Odontogenic Keratocysts and Dentigerous Cysts. J Oral Pathol Med 1990; 19: 442-446.
17. Browne RM and Gough NG. Malignant Change in Odontogenic Cyst. Cancer. 1972; 29: 11991207.

18. Li TJ, Browne RM and Matthews JE. Expression of proliferating cell nuclear antigen (PCNA) and Ki-67 in unicystic ameloblastoma. J Histopathol 1995; 26: 219-228.

19. Tsuji T, Sasaki K, Kimura Y, Yamada K, Mori M, Shinozaki F. Measurement of proliferating cell nuclear antigen (PCNA) and its clinical application in oral cancers. J Oral Maxillofac Surg 1992; 21: 369-372.

20. Pellegrini W, Facchetti F, Marocolo D, Salvi L, Capucci A, Tironi A, Rossi G. Assessment of cell proliferation in normal and pathological bone marrow biopsies: a study using double sequential immunophenotyping on paraffin sections. J Histopathol 1995; 27: 397-405. 